\title{
O DESIGN COMO A EXPRESSÃO DE FAZER AS COISAS JUNTOS: UM ENTENDIMENTO ECOLÓGICO
}

Design as to expression things together: an understanding ecological

\section{HICKEL, Denis Kern I Doutorando em Design}

Universidade Técnica de Lisboa, U.T.LISBOA, Portugal. ddesenhando@gmail.com

\section{Resumo}

Este artigo propõe uma exposição conceitual do design a partir de uma cosmovisão essencialmente ecológica e que tem como ponto de partida o entendimento do viver e do fazer humano proposto por Humberto Maturana. Assim, pretende-se uma situação do design, em toda a sua diversidade, no fluxo dos acontecimentos para possibilitar o engendramento de novos significados em contrapartida ao paradigma antropocêntrico que legitima a degradação social e ecológica em curso.

Palavras-Chave: Design. Ecologia. Cocriação. Educação.

\section{Abstract}

This paper takes into account the work of Humberto Maturana to situate design within an essentially ecological perspective. It aims to clarify the context of design, in all its diversity, within the flow of unfolding global events. It supports the idea of integrating different meanings, as opposed to the current anthropocentric paradigm that legitimates ongoing ecological degradation.

Keywords: Design. Ecology. Cocreation. Education. 


\section{INTRODUÇÃO}

Ao longo dos últimos seis anos, dediquei-me a uma pesquisa que buscou entender o design a partir de uma cosmovisão essencialmente ecológica e que teve origem na tentativa de vislumbrar o que poderia vir a ser uma escola sustentável. Nesse processo descobri que a discussão sobre a sustentabilidade não poderia estar limitada aos domínios do materializado, onde os designers têm atuado maioritariamente, mas sim ser realocada para o domínio das nossas relações mais íntimas, em como nós, ao longo do nosso viver e fazer juntos, atribuímos significado e nos movemos no mundo.

Sendo assim, foi necessário rever o curso de ação da pesquisa para detectar como o design surge dentro da ecologia das relações humanas. De forma complementar foi também criado um entendimento de como um certo modo de ser e de estar no mundo, desajustado das dinâmicas dos ecossistemas, vem colocando a presente civilização humana em um ponto de viragem sem volta. Tais entendimentos passam a constituir-se em contexto no qual transcorre a inflexão conceitual da pesquisa. Ainda, como forma de gerar um suporte empírico à reflexão conceitual, envolvi-me com a comunidade escolar da cidade de Torres Novas, Portugal, onde desenvolvi e criei exercícios para implicar os participantes em um processo criativo, no qual pudessem repensar suas escolas diante de um paradigma ecológico e pós-carbônico. É nesse meio que se estabelecem os elementos indicadores, sobre um possível papel que os designers podem ocupar neste momento de transição, na sociedade de modo geral e, particularmente nas escolas. Esse exercício e algumas das suas referências estão relatados em dois artigos anteriores (HICKEL, 2013, 2014) e não os abordarei aqui, embora seja necessário explicitar o quanto contribuíram para a presente construção.

Neste artigo, vou limitar-me à exposição conceitual do design a partir de uma cosmovisão essencialmente ecológica e que tem como ponto de partida o entendimento do viver e do fazer humano proposto por Humberto Maturana, cuja amplitude se pode incluir a aquisição de conhecimento. Essa reflexão é, portanto, complementar aos meus artigos anteriores e, apesar do cunho essencialmente teórico, torna-se essencial à medida que o atual paradigma de bem-estar antropocêntrico e ligado ao crescimento econômico não pode mais explicar, ou proteger o desenvolvimento humano. A ecologia aqui não surge como uma busca a qualquer passado idílico de proximidade com a natureza, mas apresenta-se como a construção de uma ecoliteracia. Que, conforme Orr (2002), consiste em conhecer as dinâmicas dos sistemas vivos e viver de acordo com os mesmos. O que se pretende, portanto, é perspectivar uma posição ao design, em toda a sua diversidade, no fluxo dos acontecimentos, formulando explicações alternativas que possibilitem engendrar novos significados, para a seguir, podermos cocriar e empreender alternativas ao paradigma que legitima

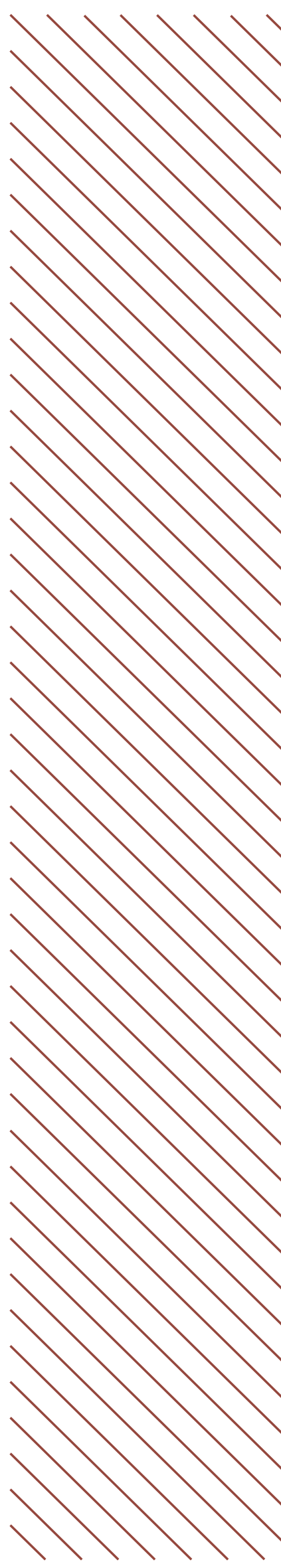


a degradação social e ecológica em curso.

\section{Um contexto crescente}

Cabe aqui contextualizar o quanto uma forma dualista de pensar e agir no mundo não permite que tenhamos em conta a nossa participação nas dinâmicas dos sistemas vivos, o que separa assim a existência humana da existência no mundo natural, ao qual chamarei de comunidade da vida (BOHM, 1980; BATESON, 2000; CAPRA, 2002; ORR, 2002; NAESS, 2008; FERRY, 2010, 2011). Essa forma de pensar, em conjunto com a noção de bem-estar atrelado à lógica de crescimento material continuado, tem provocado toda a sorte de degradação social, cultural e ecológica até o ponto de reconhecer que estamos entrando na longa descendência da nossa civilização tecno-industrial, essencialmente movida por formas concentradas de energia barata (FOSTER, 2001; GREER, 2008, 2009; HULME, 2009; JACKSON, 2009; EISENSTEIN, 2011; HEINBERG, 2011; LATOUCHE, 2011; AHMED, 2014; CHESTNEY, 2012; HOPKINS, 2014; MOTESHARREl; RIVAS; KALNAY, 2014). Destaca-se aqui a revisão dos Objetivos de Desenvolvimento do Milênio publicado pelas Nações Unidas, que reconhece como a ação humana no Planeta é cada vez maior e põe em causa mesmo as perspectivas de crescimento mais conservadoras (SDSN, 2013).

Tal contexto global deverá limitar as lógicas vigentes e questionar a própria ideia de crescimento contínuo e já não pode ser mais considerado uma mera especulação, mas um encadeamento de fatores complexos, aparentemente dispersos em um mundo globalizado, onde mesmo os bens mais essenciais são produzidos fora do escopo do nosso entendimento e trazem em si grandes porções de degradação social e ambiental.

Neste contexto de valores e significados, o debate travado no presente, sobre desenvolvimento sustentável, não passa de uma tentativa de acomodar o status quo. A nossa sociedade está empreendendo uma tentativa de adaptação para deixar intactas as estruturas que a caracterizam, tais como as suas estruturas de poder, de criação do conhecimento e de produção, o que representa a manutenção de uma determinada identidade e não a sua transformação (MATURANA; VARELA, 1984; CAPRA, 2002; HOLLICK, 2006; MEADOWS, 2009).

Ainda, por conta dessa mesma forma de pensar e estar no mundo, tais afirmações são de difícil reconhecimento pelas pessoas, ainda que os dados e as informações existentes digam o contrário (GREER, 2008, 2009; HOPKINS, 2008; HOLMGREN, 2009; HEINBERG, 2011; ODAC, 2011; ISEOF, 2012). No entanto, à medida que continuarmos legitimando essa forma de fazer, e quanto mais tempo mantivermos as coisas básicas da nossa vida - bens, 
matérias primas, energia, comida, dentre outros - longe do escopo do nosso entendimento, mais demorará para tomarmos uma atitude contra os danos que causamos. O desenvolvimento de uma crise ecológica e a dificuldade de entender a nossa participação intrínseca nessas dinâmicas suportam a ideia crescente de que deveremos todos enfrentar alguma forma de colapso das nossas estruturas materiais e imateriais neste século, caso não nos empenhemos em repensar as relações, em relocalizar a economia, em aprofundar a democracia, ou ainda, como sugere Latouche (2011), adotar um decrescimento sereno.

A propósito desta reflexão, cabe destacar que a diferença entre interpretar tais acontecimentos como essencialmente catastróficos ou, ao contrário, como a possibilidade de revelar outros aspectos dessa transição - os criativos, psicológicos, espirituais e éticos - é uma questão de valores e perspectivas de mundo que deveriam estar na pauta nas discussões. Portanto a forma de pensar que nos separa das dinâmicas dos ecossistema doravante será tratada como antropocêntrica e deveria portanto ser substituída por uma sistema de valores ecocêntrico, ou seja, que contempla a nossa participação em tais dinâmicas.

\section{Um questionamento}

Neste contexto, onde está o design? Como uma atividade essencialmente intersubjetiva, o design vem surgindo com uma atitude transdisciplinar, que ao mesmo tempo integra e é capaz de introduzir e facilitar o fluxo de informação entre diferentes domínios de conhecimento, para uma diversidade de propósitos e soluções. No entanto, naquilo que diz respeito à crise ecológica em curso, se exercido sob o mesmo sistema antropocêntrico de valores, o seu papel limita-se em como tornar "verde" os objetos de uma cultura essencialmente antropocêntrica.

Ainda que os avanços das ciências e das tecnologias da informação evidenciem um mundo em rede, os sistemas de valores não mudam no mesmo ritmo. Portanto, a problemática é a mesma: uma vez que emerge em um determinado contexto de significado e de valores, o design está maioritariamente propagando certas práticas e patologias que não são mais ecologicamente sustentáveis. Entretanto e exatamente por surgir no contexto e no fluxo das amplas dinâmicas socioculturais, é que o design - em transversalidade com outras perspectivas - pode converter-se em um ponto de ruptura da propagação de determinadas lógicas vigentes, sobretudo no campo educacional.

Resumirei essa afirmação como se segue e com o auxílio do gráfico abaixo. No eixo vertical, à medida que o design e o seu pensamento criativo movemse para atingir ampla participação na sociedade, entra em novos e diversos domínios de aplicação e prática. Ao mesmo tempo, situa-se como facilitador e integrador de diferentes perspectivas vindas de áreas diversas: das ciências 
às artes e do âmbito doméstico ao mundo dos negócios e que informam a pesquisa e a prática do design. No entanto, essas perspectivas, ao estarem sustentadas por um sistema de valores prioritariamente antropocêntrico e especialista, no qual o bem estar humano está acima das outras espécies e dos ecossistemas, faz com que a informação permaneça separada por domínios distintos de conhecimento. Por consequência, qualquer tentativa de resolver as questões de sustentabilidade ecológica a partir dessa perspectiva deverá falhar, por não reconhecer a interdependência, por confundir processos lineares com circularidade causal e por não reconhecer a essencial participação humana nas dinâmicas dos ecossistemas. Esse é o caminho da adaptação para acomodar o status quo.

No eixo horizontal, apresenta-se a possibilidade de um pensamento ecológico entrar e permear os domínios diversos do design. Este também facilita e integra outros domínios de conhecimento, mas de forma diferente, caracterizando-se por situar o design em direção a formas mais profundas de interação e entendimento ecológico, onde humano e natural fundem-se, e o bem estar dos sistemas que sustentam a vida é a intenção e o princípio primordial de toda ação. Sendo assim, a possibilidade de sustentabilidade ecológica e as expressões naturais do design confluem na cosmovisão que sustenta muitos dos avanços da humanidade, e onde a diversidade do pensamento e do conhecimento humano encontram-se com formas de participação ecológica profundas e coerentes. O alinhamento do fazer humano de acordo com as dinâmicas dos sistemas vivos representaria portanto uma nova dimensão de bem-estar humano essencialmente ecológica, ou seja, não dualista, em uma situação que necessariamente deve romper com o passo adaptativo para a acomodação. Ao romper com a organização estrutural que caracteriza a civilização tecno-industrial, promoveremos uma transmutação do pensamento humano para dar lugar a novos arranjos eco-socioculturais, o que deverá também abrir novos campos exploração e significado para o fazer humano. 
Figura 1 - Encontro entre o pensamento do design (design thinking) e um entendimento ecológico profundo

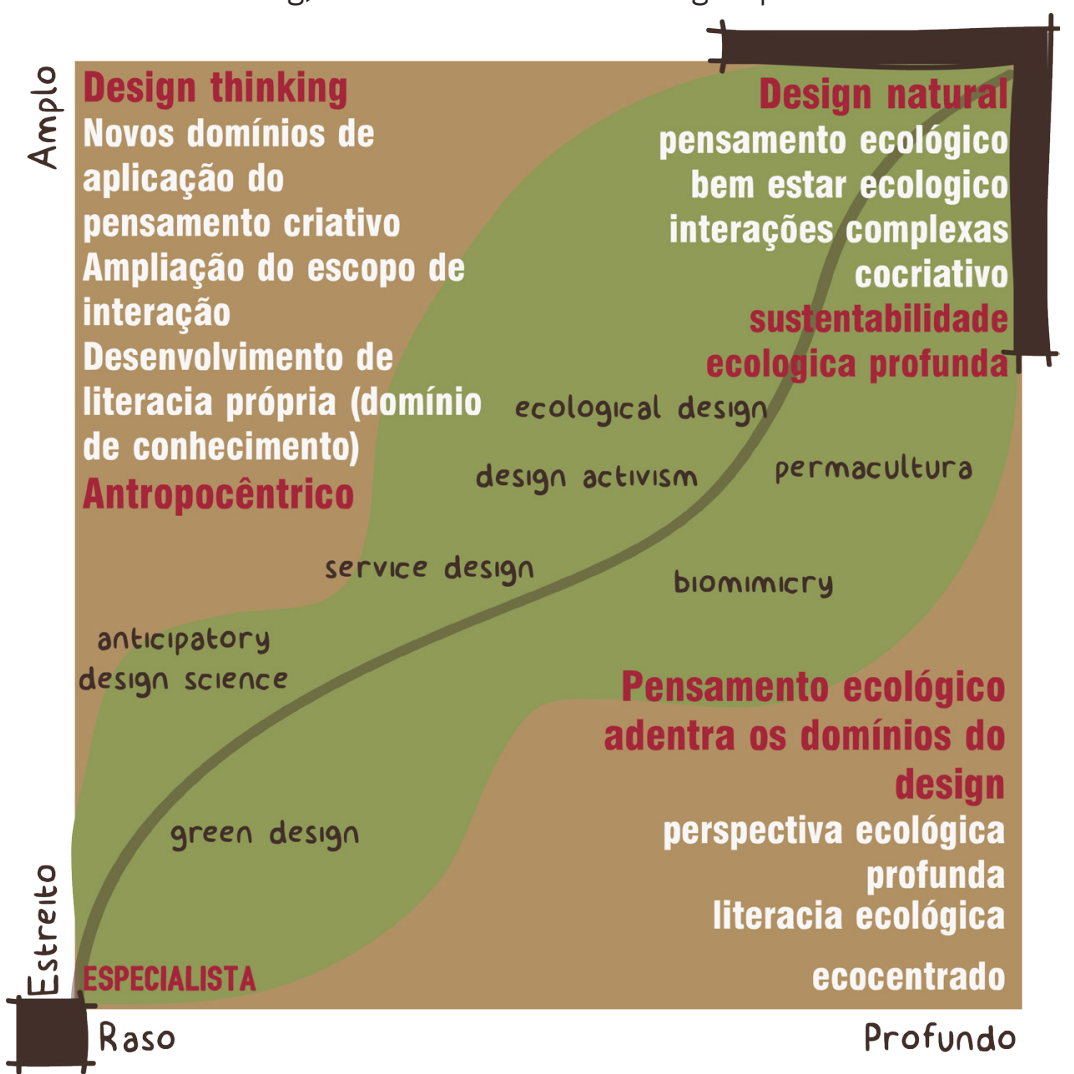

Uma questão se faz importante para o entendimento proposto: como o design surge nas dinâmicas do viver e do fazer humano? Neste sentido, o trabalho de Humberto Maturana constitui-se em uma nova amplitude à vida humana, compreendendo-a inserida nas dinâmicas dos sistemas vivos - uma cosmovisão ecológica! Acredito assim que tal cosmovisão ecológica poderá ser capaz de explicar e proteger outras formas de bem-estar, através da integração das dimensões dos domínios biológico e cultural. Ao contrário das lógicas de separação, essas explicações assumem e agregam à razão técnico-científica as experiências sensoriais da percepção e das emoções, até a possibilidade de um autoconhecimento profundo. Isto necessariamente envolve mover o foco dos aspectos materiais do design para examinar os seus domínios imateriais e, assim, explorar e criar entendimento sobre os níveis de abstração cognitivos que permitem-nos criar imagens mentais, formular crenças e valores, senso de identidade, agir intencionalmente e comunicar através de linguagem simbólica, que juntos conectam a complexa rede da cultura humana à rede dos sistemas vivos (MATURANA; VARELA, 1984; MATURANA, 1988, 1999, 2002; MATURANA; VERDEN-ZOLLER, 1996; MATURANA; REZEPKA, 1997; MATURANA; DAVILA, 2012).

\section{O design na ecologia do viver e do fazer humano}

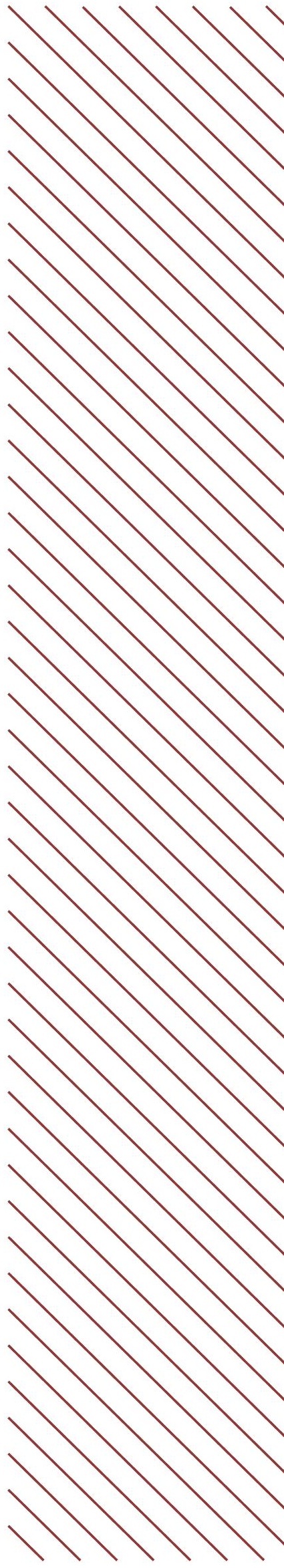


O eixo central para essa proposição encontra suporte em Maturana, com a afirmação de que nós, seres humanos, vivemos em interação comunicativa, onde a natureza simbólica da linguagem envolve a comunicação de significados. É portanto através da atribuição de significados ao entorno que nós criamos os nossos mundos, compartilhando formas subjetivas e objetivas, envolvendo consciência individual e coletiva que, por sua vez, é dependente de contextos, valores, crenças e circunstâncias. É portanto em conversação que os objetos que fazem parte da nossa cultura emergem como aspectos da nossa comunicação com os outros (MATURANA, 1988; CAPRA, 2002). Sendo assim, como explicado por Maturana (2002, p. 28):

[...] Os objetos e quaisquer outras entidades que surgem na comunicação pertencem a um domínio de intersubjetividade com outros seres falantes, com os quais nós geramos os objetos e outras entidades que constituem tal domínio [...] Viver na comunicação é viver num domínio de objetos partilhados e em intersubjetividade.

São nesses domínios de intersubjetividade que constituímos as redes e processos de conhecimento da nossa própria existência. Características estas que são parte de toda a nossa evolução enquanto seres vivos. Sendo assim, foi e é, ao viver e fazer as coisas juntos, que estabelecemos as nossas culturas como uma totalidade de padrões de comportamento transmitidos socialmente. Portanto, de acordo com as explicações de Maturana e também do físico Fritjof Capra (2002), todos os fenômenos que são parte essencial da vida humana social - regras de comportamento, valores, intenções, objetivos, estratégias, designs, relações de poder - seja qual for a sua diversidade, são organizadas numa rede de relações assim como os demais sistemas vivos.

Capra (2002) destaca no trabalho de Humberto Maturana esta conexão entre as redes humanas e os sistemas vivos, propondo olhar para os mesmos a partir de quatro perspectivas interconectadas: da forma, da matéria, dos processos e dos significados - onde a forma e a matéria são integradas por meio de processos. Aos processos, Maturana classifica-os como cognitivos, pois ao longo da vida os organismos estão num processo contínuo de "conhecimento" ao estar constantemente respondendo e congruentemente adaptando junto com o meio. Enquanto seres vivos, o mesmo acontece ao longo da ontogenia dos seres humanos. Ou seja, como afirma Maturana, viver é saber. A extensão deste fenômeno para o mundo sociocultural humano dá-se através de uma quarta perspectiva: à medida que comunicamos, atribuímos significados para o nosso entorno e portanto, após forma, matéria e processos, através dos significados, nós nos encontramos e nos relacionamos com o mundo. 
Sendo assim, a nível biológico, uma célula, por exemplo, consiste em uma rede (forma) de reações químicas (processos) que envolvem a produção dos componentes da célula (matéria). Estas respondem cognitivamente e coerentemente, através de alterações estruturais auto direcionadas (processos) às perturbações do seu ambiente (CAPRA, 2002, p. 62). Assim se passa, em diferentes níveis de complexidade, com todos os sistemas vivos, incluindo aí, seres humanos e suas redes. Capra sustenta a posição de Maturana, em que, de acordo com suas palavras:

\begin{abstract}
Todos estes fenômenos cognitivos são não materiais, mas estão corporificados - eles surgem e são formados pelo corpo. Portanto a vida nunca está divorciada da matéria, ainda que as suas características essenciais — organização, complexidade, processos e assim por diante - sejam não materiais (CAPRA, 2002, p. 63).
\end{abstract}

Assumindo a existência biológica como sistemas vivos, podemos estender a explicação desses fenômenos para as relações sociais humanas: uma determinada cultura, por exemplo, é criada e sustentada por uma rede (forma) de comunicações (processos), através dos quais significados são gerados. As corporificações materiais da cultura (matéria) incluem artefatos, objetos, textos escritos, e assim por diante, através dos quais determinados significados são passados de geração para geração (CAPRA, 2002, p.64). Portanto, enquanto sistemas vivos, somos seres sociais que partilham o mesmo princípio de organização em rede com a totalidade da comunidade da vida, onde as nossas relações socioculturais são parte do mundo natural, como sistemas dentro de sistemas.

Malcolm Hollick (2006, p. 84-85), sobre o mesmo tema, faz uso do termo cunhado por Arthur Koestler, holons e holarquias. De forma resumida, refere-se ao universo, entendido como composto por sistemas e subsistemas, onde cada entidade é ao mesmo tempo um todo e uma parte. Uma entidade é um sistema completo em si - um holon - e simultaneamente um subsistema dentro de um todo maior. Uma holarquia descreve as relações entre holons em diferentes níveis de organizações tais como átomos e moléculas, ou células e organismos e assim por diante.

De forma complementar, Donella Meadows (2009) descreve um sistema e suas relações como um determinado conjunto de elementos coerentemente interconectados, onde estão necessariamente presentes elementos, interconexões e uma função, ou propósito. Como ela exemplifica, um animal é um sistema, uma árvore é um sistema inserido em um sistema maior que é a floresta que também envolvem outros subsistemas de árvores, animais e

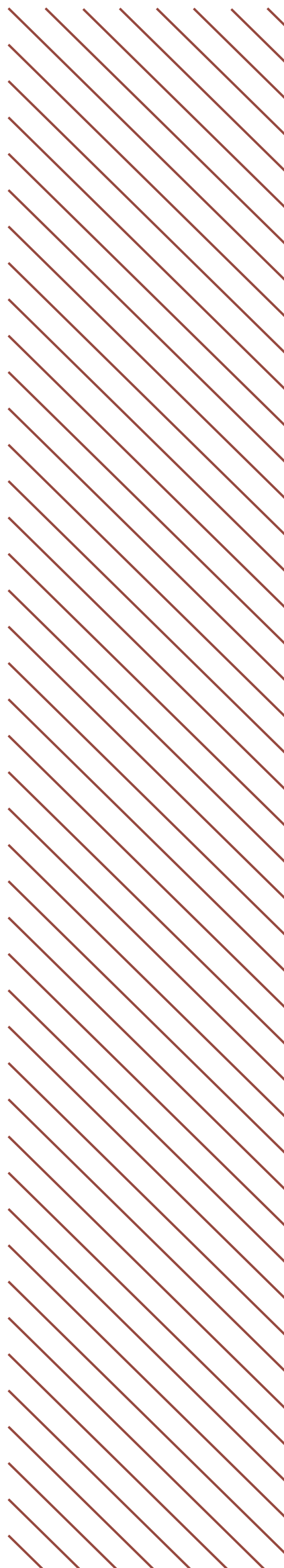


outros seres até outros sistemas que compõem a biosfera. Da mesma forma, os sistemas humanos, como as culturas, escolas, uma fábrica, uma cidade, a economia e outros, são sistemas dentro de sistemas que estão interconectados, onde estes cumprem determinadas funções e com determinados propósitos (MEADOWS, 2009, p. 12). Nas palavras de Capra (2002, p. 70):

\begin{abstract}
A todos os níveis da vida, das redes metabólicas das células para as redes alimentares dos ecossistemas - os componentes e os processos dos sistemas vivos estão interligados em redes. Estender um entendimento dos sistemas vivos para os domínios do social, portanto, significa aplicar nosso conhecimento destes para a realidade social.
\end{abstract}

As sociedades e suas culturas e estruturas são sistemas vivos, pois estes envolvem seres humanos em comunicação e constante interação com o meio de sua existência. Isto também as faz sistemas cognitivos que geram a si próprias. Conforme a explicação dada por Capra, cada comunicação cria pensamentos e significados que levam a mais comunicações e então toda a rede cria a si própria. As comunicações recorrem em ciclos de retroalimentação, produzindo uma rede de crenças, explicações e valores partilhados, ou seja, um contexto comum de significado.

Portanto, é ao viver e fazer as coisas juntos que constituímos as nossas redes de comunicação e certas perspectivas culturais, valores e explicações que estabelecem certas formas de estar no mundo. Uma rede complexa de relações entre humanos e seus lugares, que evoluem e mudam de acordo com as circunstâncias naturais e culturais, onde uma certa cultura é um contexto comum de significado que se retroalimenta constantemente, regenerando a si própria.

Os contextos que criamos são feitos de coisas materiais e objetos aos quais atribuímos significados e que também contribuem para passar uma determinada cultura de geração para geração ao facilitar ou intermediar certo modus vivendi. O design - em todas as suas disciplinas e instâncias de ação surge nesses domínios de relacionamento inerentes ao viver e fazer humano.

Entre os "designs" portanto - qualquer ato, intenção, ou projeção em direção ao futuro - são todos criados através de nós, com certos propósitos e carregando significados. É através do design que materializamos valores, crenças e intenções que permeiam os nossos mundos interiores: todas as estruturas materiais que surgem da rede de interações humanas constantemente estabelecendo a rede da cultura vêm através do design em 
processos de influência mútua; todas as comunicações visuais e simbólicas; objetos, atividades e serviços organizacionais; sistemas complexos e ambientes para as atividades humanas e assim por diante.

O design, portanto, intermedia os processos que conferem significado à matéria, a transformação do natural, ou dos elementos brutos em uma miríade de sistemas e objetos e que podem tanto promover como danificar certas condições ecológicas e portanto empobrecer ou enriquecer o viver. À medida que, na ontogênese de uma cultura civilizacional, o ser humano criou nichos, repartiu o conhecimento e especializou-se, o design também o fez. Ainda que a criatividade, o planejar e o projetar em direção ao futuro seja uma característica essencialmente humana, por questões socioculturais, o pensamento criativo o "design thinking" - também foi conferido a especialistas.

No entanto, ainda que esteja maioritariamente limitado a contextos de especialidade do conhecimento, "o fazer design" é, em termos ecológicos, a expressão natural de fazer as coisas juntos que é inerente à ecologia humana. Dentro desta perspectiva, designers, ou não, a nossa responsabilidade individual e coletiva é total. Tudo o que materializamos é naturalmente o resultado de uma rede de relações eco culturais, perspectivas e sistemas de valores que estão intimamente conectados com as dimensões subjetivas do ser.

Visto isso, somos portanto mais que intérpretes racionais e passivos de um suposto mundo a explorar e dominar - nós somos participantes interativos das dinâmicas sociais e ecológicas em corpo, fala e mente. O que separou-nos como seres discretos e competitivos, especialistas e fora do mundo natural foi uma certa forma de pensar - uma cosmovisão, uma concepção do universo e a relação da humanidade com este. A ideia de separação entre os domínios do humano e do natural e consequentemente a ideia de comando e controle sobre o caótico, o complexo e o inesperado são parte de uma ideologia que define a nossa civilização tecno-industrial (FERRY, 2010, 2011; EISENSTEIN, 2011). Uma ideologia que, em face da crescente degradação ambiental, não é mais capaz de explicar, prever ou proteger o desenvolvimento humano.

Se acordarmos que o atual consumo de recursos naturais é maior do que o planeta pode regenerar e que vem colocando as estruturas de civilização tecno-industrial (um determinado sistema de valores, crenças e explicações) em xeque-mate, isto dá suporte ao que afirmei no início: o que estamos fazendo quando debatemos um certo desenvolvimento sustentável, é uma adaptação, pois ao não promover questionamentos sobre como atribuímos significados e sistemas de valores deixa-se intacta determinadas estruturas de valores que legitimam a degradação ecológica em curso. Dito de outro 
modo, estamos essencialmente tentando manter o paradigma vigente, uma identidade confortável, mas que encontra-se condenada por falta de recursos e por perda de resiliência ecológica; um padrão repetitivo na ascensão e queda de civilizações humanas passadas (GREER, 2008).

Esse é o motivo pelo qual torna-se necessário articular novas perspectivas de mundo capazes de reunir o que está separado e engendrar novos contextos de significados e sistemas de valores. O primeiro entendimento fundamental que surge dessa explicação - que é a raiz de uma perspectiva essencialmente ecológica - é o da interdependência do viver humano com as dinâmicas complexas dos sistemas vivos e que, portanto, a saúde humana é também intrinsecamente interdependente com a saúde dos ecossistemas.

É por esta razão que os designers - e outros especialistas do saber humano - não podem responder as questões sociais e ambientais emergentes a partir do mesmo contexto cultural que legitimou a separação e a degradação inicialmente. A disciplina do design vem experimentando uma transformação revolucionária, ampliando o escopo da sua atividade para além dos discursos sobre forma e função (BUCHANAN, 1995; MARGOLIN, 2007; MARKUSSEN, 2012). Ainda que tenha crescido como uma especialidade, com seus diversos nichos, os participantes dos domínios do design, cada vez mais, vêm de diversos contextos de conhecimento, profissões e áreas acadêmicas que se aproximam por um interesse mútuo na concepção e no planejamento do mundo material. $O$ encontro do design com um pensamento ecológico permite ainda uma situação subsequente: entender os processos criativos do design como um domínio intersubjetivo de relacionamento e portanto um possível espaço para promover rupturas e alterações culturais.

\section{O design como domínio intersubjetivo de relacionamentos: o solo fértil}

Quando as pessoas, ao viver e fazer as coisas juntas, entram em comunicação, elas estabelecem um espaço comum de relacionamento. De acordo com o termo utilizado por Maturana, estes são domínios intersubjetivos. Tais espaços, domínios, ou plataformas, configuram-se como múltiplas possibilidades de engendrar significados e outras realidades, onde através da participação interativa, os indivíduos podem criar o entendimento do seu lugar nos processos eco culturais que descrevi acima.

A importância desses domínios prende-se pelo fato de que numa sociedade tão setorizada é o próprio campo do design que pode devolver às pessoas a experiência viva da participação em processos que não limitam-se apenas à materialização de objetos de consumo. Criar com os outros envolve também pessoas não familiarizadas aos domínios do design, trabalhando juntas ao longo de todo o processo criativo e até mesmo na sua materialização. Isso 
cria um estado de coautoria de projetos e sonhos, em igualdade de estatura e conhecimentos, únicos e relevantes para o processo. Como ensina Elizabeth Sanders, o termo "cocriação" diz respeito a "qualquer ato de criatividade coletiva, como por exemplo, criatividade partilhada por duas ou mais pessoas". Onde a sua aplicação pode variar "do físico ao metafísico e do material ao espiritual" (SANDERS; STAPPERS, 2008, p. 2).

O trabalho realizado por Sanders constitui-se também em evidência empírica das afirmações que venho elaborando (SANDERS, 2002; SANDERS; WILLIAM, 2003; SANDERS, E., 2005; SANDERS, E. B. N., 2005; SANDERS, 2006; SANDERS; CHAN, 2006; SANDERS; STAPPERS, 2008; SANDERS, 2009; SANDERS; SIMONS, 2009; SANDERS; BRANDT; BINDER, 2010; SANDERS; WESTERLUND, 2011). A referência teórica que complementa esse entendimento está presente no trabalho da professora Sandra Jovchelovitch, que parte do conceito de esfera pública de Habermas para enfatizar a importância psicológica da interação em processos participativos, em explicações que se encontram com as de Maturana sobre a ontogénese da existência humana. Jovchelovitch define a esfera pública como o espaço conceitual, onde os processos de socialização - comunicação e entendimento - acontecem. Portanto, constitui-se também em espaço, domínio, ou plataforma intersubjetiva. São nesses espaços que constituímos nossos sistemas de valores, ideias, crenças e práticas que partilhamos e que são, portanto espaços para o surgimento de realidades intersubjetivas, da participação pública e da possibilidade de democracia (JOVCHELOVITCH, 1995, 2007; CAMPBELL; JOVCHELOVITCH, 2000). Sendo assim, de acordo com Jovchelovitch (2007 p. 4), a importância desses processos reside no fato de que a participação na vida social é:

Enraizada no processo pelo qual o indivíduo humano desenvolve uma identidade, cria símbolos e abre-se para a diversidade do mundo dos outros [...] o individual, em si próprio, é o resultado de um processo de socialização [...] individualização e socialização são aspectos diferentes do mesmo processo na ontogênese da experiência humana.

Os processos através dos quais formamos as nossas representações estão embutidos nas práticas sociais e comunicativas dos domínios intersubjetivos em que escolhemos tomar parte:

[...] Diálogos, fala, rituais, padrões de trabalho, produção e arte, em resumo, mediação social [...] Comunicar é mediar entre um mundo de perspectivas infinitamente diferentes; trabalhar é mediar entre as necessidades humanas e as matérias-primas da natureza; desenvolver ritos, mitos e 
símbolos é mediar a alteridade de um mundo quase sempre misterioso e o mundo da mente humana; todos estes revelam, em maior ou menor extensão, a busca humana para dar sentido e significado para a sua existência no mundo (JOVCHELOVITCH, 1995, p. 81-102).

Portanto, quando o designer intencionalmente ativa, integra e facilita certos domínios intersubjetivos no fluxo das comunicações e negociações regulares, que são também cocriativos, funda-se a possibilidade de interação consciente entre diferentes indivíduos em processos que podem ser transformadores. Pois é através da participação interativa, quando envolvemo-nos com outros indivíduos para afirmar um projeto comum, que compreendemos, situamos e conferimos significados para o viver, criamos consciência dos nossos recursos, circunstâncias e identidade. A participação, como referiu Jovchelovitch, levanos de encontro à ideia de conscientização proposta por Paulo Freire, como sendo os processos de construção de consciência crítica sobre si mesmo e o mundo (CAMPBELL; JOVCHELOVITCH, 2000, p. 4).

A ideia do design como plataforma de princípios, um domínio intersubjetivo e cocriativo, ultrapassa as tradicionais formas intencionais de estar juntos para produzir os objetos e produtos da nossa cultura consumista. O processo de participação interativa em si e as intenções permeando o processo ganham evidência. Portanto, estar juntos para cocriar plataformas para engendrar possíveis formas de viver de acordo com as dinâmicas dos sistemas vivos e criar consciência da nossa própria participação em tais dinâmicas constitui-se na mais pura forma de ativismo pelo design.

O ativismo pelo design ocorre quando este se encontra em posição de fomentar e suportar mudanças sociais, quer pela promoção de certos valores, quer pelo questionamento sobre determinados padrões de comportamento social (PREECE, 2011; MARKUSSEN, 2012, p. 38; HICKEL, 2014). Nestas circunstâncias os designers assumem o papel de ativadores, facilitadores e integradores de tais plataformas, para fundamentalmente, promover a interação das pessoas para imaginar, criar e empreender outras formas de viver. Este foi o tema central da minha pesquisa exploratória com a comunidade escolar de Torres Novas, quando convidei-os a imaginar as suas escolas em um contexto de energia descendente e a partir da exploração de léxicos ecológicos (HICKEL, 2014). Ainda que com limitações, essa experiência vivida é também base para essa reflexão teórica sobre os processos criativos do design como espaço para transformação pessoal e coletiva. 


\section{CONCLUSÃO}

Uma das ideias centrais do pensamento de Maturana - essencial nesta transição que proponho - é que a cognição, ou o processo de aprendizagem, é inerente à experiência do viver. Isso tem uma implicação na nossa civilização e na nossa atual situação ecológica, uma vez que o conhecimento está, em larga escala, institucionalizado e pertencente ao domínio do experimento científico e das instituições de ensino. Isso, de acordo com autores como Lorraine Code (2006) e Giorgio Agamben (2005), provoca um deslocamento do conhecimento humano para fora do contexto onde os problemas emergem e poderiam ser resolvidos. Isso aplica-se de especial maneira à forma como lidamos com as mais diversas questões a partir de uma perspectiva que nos separa das dinâmicas naturais.

Uma situação do viver e do fazer dentro de perspectivas essencialmente ecológicas possibilita, portanto, fomentar novos engendramentos que podem questionar e oferecer alternativas à cosmovisão antropocêntrica dominante. Aos designers, o professor David Orr (2002) propôs um termo para esta situação que é a Literacia Ecológica. Ele sugere que em face das questões sócio ecológicas em curso, os designers devam tornar-se pessoas eco literatas. Ou seja, conhecer as dinâmicas dos ecossistemas e viver de acordo (Orr, 2001, 2002, 2005a, 2005b).

Seguindo essa premissa, sugiro abandonar o debate atual da agenda pelo desenvolvimento sustentável - que é uma tentativa de acomodação do presente sistema de valores à uma situação fisicamente impossível - para, a partir de uma ecoliteracia, fundar uma agenda de sustentabilidade ecológica profunda. Este termo é um tributo à definição de ecologia profunda de Arne Naess (2008, p. 27), que enfatiza o valor intrínseco de todas as criaturas e valoriza todas as formas de diversidade biológica e cultural. Ao contrário de outras discussões sobre uma cultura ecocêntrica, ou mesmo sobre ecologismos (FERRY, 1995), este não significa a sobrevalorização de nenhuma espécie ou modelo de ser e estar, mas sim, o entendimento da interdependência entre o mundo social humano e o mundo natural e uma nova situação do fazer dentro das suas dinâmicas. Neste caso a ecologia não deve ser entendida como mais um problema, ou assunto com o qual temos de lidar, mas sim como a casa que habitamos.

Assim sendo, e entendendo que toda ação humana no mundo corporifica e materializa determinadas intenções, aspirações e valores eco culturais, em nome de uma sustentabilidade ecológica profunda, deveríamos intencionalmente fundar domínios de relacionamento cocriativo, para entender e viver de acordo com as dinâmicas dos ecossistemas. Nesse contexto, o objetivo comum de todo o design humano deveria ser o de promover, facilitar e sustentar o bem-estar

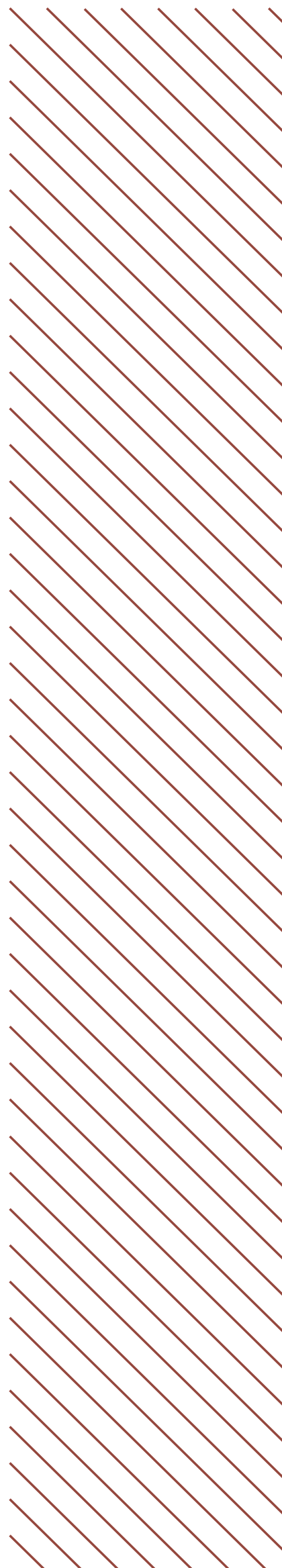


dos processos ecológicos que sustentam a vida humana na terra como pilares de proteção e prosperidade da humanidade.

Isso obviamente inclui todas as estruturas materiais que surgem da rede de interações constantemente sustentando as diferentes nuances das culturas humanas: todas as comunicações visuais e simbólicas; objetos, atividades e serviços organizacionais; sistemas complexos e ambientes para as atividades humanas e assim por diante. No entanto, ganham importância sobre o mundo materializado as relações e os processos criativos que se fundam nos domínios de relacionamento criativo e que oferecem espaço para transformação pessoal e coletiva.

Em face do que ofereci com este ensaio e da complexidade crescente e também da volatilidade do meio em que o design acontece, torna-se necessário rever o suporte intelectual do fazer humano, refletir sobre o significado destas tendências e suas implicações éticas. Como afirmei, a transição em curso para uma economia pós-carbônica não previne que esta civilização venha a sofrer maiores colapsos ao longo deste século, apesar de toda a confiança geral na tecnologia e no conhecimento especializado - porém compartimentalizado. A crescente individualização, a competição e o hedonismo geral na sociedade nada mais faz do que agravar a divisão e o mal-estar.

No entanto, se o aviso de colapso não foi apelativo nos últimos 50 anos, então, com este ensaio, eu proponho que o convite a cocriação de alternativas possa vir a ser uma alternativa viável. Tal afirmação é coerente com a ideia de que somos seres essencialmente sociais e que diante disso as possibilidades que daí podem resultar ainda estão por ser imaginadas. Uma situação do nosso viver e do nosso fazer dentro de uma perspectiva essencialmente ecológica é uma possibilidade de situar as representações sociais humanas - que forçosamente inclui o quê e como projetamos e materializamos - dentro de um domínio intersubjetivo que reconhece diferentes perspectivas e epistemologias, a riqueza da diversidade, a revalorização e reinvenção do lugar, bem como uma nova dimensão da humanidade, consciente de pertencer às dinâmicas planetárias.

Em contraste com o atual passo em direção à acomodação, isso representaria a transmutação do pensamento humano, um passo ousado para o desconhecido do que ainda está por vir. Tendo em conta o exposto, não vejo outra forma de construir uma prática coerente que seja diferente de um aprender pelo fazer profundamente enraizado na vivência dos lugares e suas dinâmicas. Sem que isso signifique a perda da autonomia, desde já deveríamos começar a questionarmos como será possível estabelecer um determinado modo de vida dentro daquilo que é o escopo de entendimento de um indivíduo 
e de suas comunidades. Quer dizer, como viver dentro dos limites onde se possa compreender, responsabilizando-se e rapidamente respondendo aos desequilíbrios e efeitos negativos gerados pela própria ação? Por fim, esta reflexão não é politicamente inocente, definitiva, nem livre de questionamentos, mas essencialmente contém as sementes para a transmutação.

\section{REFERÊNCIAS}

AGAMBEN, G. Infância e História: destruição da experiência e origem da história. Belo Horizonte: Ed. UFMG, 2005.

AHMED, D. N. Nasa-funded study: industrial civilisation headed for 'irreversible collapse'? Environment, London, 2014. Disponível em:<http://www.theguardian. com/environment/earth-insight/2014/mar/14/nasa-civilisation-irreversiblecollapse-study-scientists>. Acesso em: 10 Mar. 2012.

BATESON, G. Steps to an ecology of mind. Chicago: University of Chicago Press, 2000.

BOHM, D. Wholeness and the Implicate Order. London: Routledge \& Kegan Paul, 1980

BUCHANAN, R. Wicked Problems in Design. In: MARGOLIN, V. \& BUCHANAN, R. (eds.) The idea of Design: A Design Issues Reader. Cambridge: MIT Press, 1995.

CAMPBELL, C.; JOVCHELOVITCH, S. Health, community and development : towards a social psychology of participation. Journal of community and applied social psychology, v. 10. n. 4,.p. 255-270, 2000.

CAPRA, F. The Hidden Connections. London: Flamingo, Harper Collins, 2002.

CHESTNEY, N. 100 million to die by 2030 if world fails to act on climate. New York, 2012. Disponível em:<http://www.reuters.com/article/2012/09/27/us-climateinaction-idUSBRE88Q0ZJ20120927 >. Acesso em: 10 Mar. 2014.

CODE, L. Ecological Thinking: the politics of epistemic location. Oxford: Oxford University Press, 2006.

EISENSTEIN, C. Sacred Economics: money, gift, and society in the age of transition. Berkley: Evolver Editions, 2011.

FERRY, L. The New Ecological Order. Chicago: The University of Chicago Press, 1995.

FERRY, L. A revolução do amor: Por uma espiritualidade laica. Rio de Janeiro: Objetiva, 2010. 
FERRY, L. A Brief History of Thought. New York: Harper Collins Publishers, 2011.

FOSTER, J. B. The Vulnerable Planet: a short economic history of the environment. New York: Montley Revew Press, 2001.

GREER, J. M. Long Descent: a user's guide to the end of the industrial Age. Gabriola Island: New Society Publishers, 2008.

GREER, J. M. Ecotechnic Future: envisioning a post-peak world. Gabriola Island: New Society Publishers, 2009.

HEINBERG, R. The End of Growth: adapting to our new economic reality. Gabriola Island: New Society Publishers, 2011.

HICKEL, D. K. Co-design: setting relational domains for deep sustainability. Convergências - Revista de Investigação e Ensino das Artes (online), v. 12, 2013. Disponível em:<http://convergencias.esart.ipcb.pt/artigo/165>. Acesso em: 12 Dez. 2013.

HICKEL, D. K. Design as a Platform to Build Deep Sustainability: Reflections Around an Ideation Exercise with Portuguese Schools. International Journal of Designs for Learning, v. 5, n. 1, p. 1-11, 2014.

HOLLICK, M. The Science of Oneness: a worldview for the twenty-first century. Winchester, U.K.: Books, 2006.

HOLMGREN, D. Future Scenarios: how communities can adapt to peak oil and climate change. Totnes: Green Books, 2009.

HOPKINS, R. The Transition Handbook: from oil dependency to local resilience. Totnes: Green Books, 2008.

HOPKINS, R. Rob Hopkins' Letter to BBC Slams Climate Denier Nigel Lawson. Hampshire, 2014. Disponível em:<http://www.permaculture.co.uk/news/ 1402144366/rob-hopkins-letter-bbc-slams-climate-denier-nigel-lawson >. Acesso em: 10 Fev. 2014.

HULME, M. Why we disagree about climate change: understanding controversy, inaction and opportunity. Cambridge: Cambridge University Press, 2009.

ISEOF. The Oil Drum: discussions about energy and our future. Fort Collins, 2012. Disponível em:<http://www.theoildrum.com/>. Acesso em: 10 Fev. 2014. 
JACKSON, T. Prosperity without growth : economics for a finite planet. London; Sterling, VA: Earthscan, 2009.

JOVCHELOVITCH, S. Social representations in and of the public sphere: towards a theoretical articulation. Journal for the theory of social behaviour, London, v. 25, n. 1, 81 p., 1995.

JOVCHELOVITCH, S. Knowledge In Context: Representations, community and culture. London: Routledge Publications, 2007.

LATOUCHE, S. Pequeno tratado do decrescimento sereno. Lisboa: Edições 70, 2011.

MARGOLIN, V. Design, the Future and the Human Spirit. Design Issues, Volume 23, Number 3, 2007.

MARKUSSEN, T. The Disruptive Aesthetics of Design Activism: Enacting Design Between Art and Politics. Design Issues, v. 29, n. 1, 2012. Disponível em: <http:// www.mitpressjournals.org/doi/pdf/10.1162/DESI_a_00195>. Acesso em: 10 Fev. 2014.

MATURANA, H. Ontology of Observing - The Biological Foundations of Self Consciousness and the Physical Domain of Existence. Conference workbook: Texts in cybernetics. In: AMERICAN SOCIETY FOR CYBERNETICS CONFERENCE, Felton, 1988, CA, USA. Disponível em: <http://ada.evergreen.edu/ arunc/texts/ cybernetics/ oo/oo3.pdf >. Acesso em: 10 Fev. 2014.

MATURANA, H. Emoções e linguagem na educação e na política. Belo Horizonte: Ed. UFMG, 1999.

MATURANA, H. Autopoiesis, Structural Coupling And Cognition: A History Of This And Other Notions In The Biology Of Cognition. Cybernetics and Human Knowing, v. 9, n. 3, 34 p, 2002.

MATURANA, H.; DAVILA, X. Um Diálogo sobre infância, ética e amor. São Paulo: Instituto Alana, 2012 . Disponível em: <http://www.youtube.com/watch?v= bhkrB8WntNA>. Acesso em: 12 Jun. 2013.

MATURANA, H.; VARELA, F. J. A Árvore do Conhecimento: As Bases Biológicas da Compreensão Humana. 8. ed. São Paulo: Palas Athenas, 1984.

MATURANA, H.; VERDEN-ZOLLER, G. Biology of Love: G.: Peterander,F. (Hrsg.): Focus Heilpadagogik, Ernst Reinhardt, Munchen/Basel 1996. Disponível em: <http:// www.lifesnaturalsolutions.com.au/documents/biology-of-love.pdf $>$. Acesso em: 12 
Jun. 2014.

MATURANA, H. R.; REZEPKA, S. N. D. Human Awareness: Understanding The Biological Basis Of Knowledge And Love In Education. In: CONFERENCE OF THE INTERNATIONAL ASSOCIATION FOR COGNITIVE EDUCATION, 6., 1997, Stellenbosch.

MEADOWS, D. H. Thinking in Systems. London: Earthscan 2009.

MOTESHARREI, S.; RIVAS, J.; KALNAY, E. Human and nature dynamics (HANDY): modeling inequality and the use of resources in the collapse or sustainability of societies. College Park, 2014.

NAESS, A. Ecology of Wisdom: Writings by Arne Naess. Edited by Alan Drengson and Bill Devall. Berkley: Counterpoint Press, 2008.

ODAC. The Oil Depletion Analysis Centre (ODAC). London, 2011.

ORR, D. Prefácio. In: STERLING, S. Sustainable Education: Re-visioning Learning and Change. Totnes: Green Books, 2001.

ORR, D. The Nature of Design. New York: Oxford University Press, 2002.

ORR, D. Prefácio . In: STONE, M. K.; BARLOW, Z. (Ed.). Ecological Literacy: educating our children for a sustainable world. San Francisco: Sierra Club Books, 2005a.

ORR, D. Place and Pedagogy In: STONE, M. K. e BARLOW, Z. (Ed.). Ecological Literacy: educating our children for a sustainable world. San Francisco: Sierra Books, $2005 \mathrm{~b}$.

PREECE, G. S. Co-Designing in Love: Towards the Emergence and Conservation of Human Sustainable Communities. 2011. 424p.Thesis (Doctor of Phylosophy) Centre for the Study of Natural Design - Duncan of Jordanstone College of Art and Design University of Dundee, Dundee.

SANDERS, E. Design Serving People. In: PROCEEDINGS CUMULUS CONFERENCE ON FUTURE DESIGN AND INNOVATION, 2005, Danmarks Designskole. Disponível em: <http://www.cumulusassociation.org/images/stories/Working_papers/WP_ Copenhagen_15_05.pdf>. Acesso em: 12 set. 2014.

SANDERS, E. B.-N. Information, Inspiration and Co-creation. In: INTERNATIONAL CONFERENCE OF THE EUROPEAN ACADEMY OF DESIGN, 6., 2005. Bremen, Germany. Disponível em:<http://www.maketools.com/articles-papers/Information InspirationandCocreation_Sanders_05.pdf>. Acesso em: 12 set. 2014. 
SANDERS, E. B.-N. Design Research in 2006. Design Research Quaterly, v.1, p. 1, Sept. 2006.

SANDERS, E. B.-N. Contextmapping / Exploring Co-creation on a Large Scale. Collegerama. Delft: Technical University of Delft, 2009. Disponível em: <http://collegerama.tudelft.nl/mediasite/SilverlightPlayer/Default. aspx?peid=35aOffdf188342f7a7b39c0e212d531d >. Acesso em: 4 out. 2014.

SANDERS, E. B.-N.; BRANDT, E.; BINDER, T. A Framework for Organizing the Tools and Techniques of Participatory Design. In: PROCEEDINGS OF THE 11TH BIENNIAL PARTICIPATORY DESIGN CONFERENCE, 10., 2010, Sidney. New York, NY, ACM, 2010. Disponível em <http://dl.acm.org/citation.cfm?id=1900476\&dl=ACM\&coll= DL\&CFID=72850900\&CFTOKEN $=41918960>$.

SANDERS, E. B.-N.; CHAN, P. K. Emerging Trends in Design Research: Changes over time in the landscape of design research. Make Tools. Columbus, Ohio, USA: The Ohio State University, 2006.

SANDERS, E. B.-N.; STAPPERS, P. J. Co-creation and the new landscapes of design. CoDesign: International Journal of CoCreation in Design and the Arts, v.4, n.1, p. 5-18, 2008.

SANDERS, E. B. N.; WESTERLUND, B. Experiencing, Exploring and Experimenting in and with Co-design Spaces. In: NORDIC DESIGN RESEARCH CONFERENCE - MAKING DESIGN MATTER!, 4., 2011, Aalto University, Helsinki.

SANDERS, E. B. N.; WILLIAM, C. T. Harnessing People's Creativity: Ideation and Expression through Visual Communication. In: LANGFORD, J.; MCDONAGH, D. (Ed.). Focus Groups: Supporting Effective Product Development. New York: Taylor and Francis, 2003.

SANDERS, E. B. N. From User-Centered to Participatory Design Approaches. In: FRASCARA, J. (Ed.). Design and the Social Sciences. London: Taylor \& Francis Books Limited, 2002.

SANDERS, L.; SIMONS, G. A social vision for value co-creation in design. Open Source Business Resource, 2009. Disponivel em:<http://www.osbr.ca/ojs/index.php/osbr/ article/view/1012/973>. Acesso em: 10 Maio 2013.

SDSN. An Action Agenda for Sustainable Development: sustainable development solutions network (SDSN), a global initiative for the United nations. New York, 2013. 